Old Dominion University

ODU Digital Commons

\title{
United or Divided? Antecedents of Board Cohesiveness in International Joint Ventures
}

\author{
Rene Olie \\ Elko Klijn \\ Old Dominion University, eklijn@odu.edu \\ Hugo V. Leenders \\ Old Dominion University, hleen001@odu.edu
}

Follow this and additional works at: https://digitalcommons.odu.edu/management_fac_pubs

Part of the Business Administration, Management, and Operations Commons, and the International Business Commons

\section{Original Publication Citation}

Olie, R., Klijn, E., \& Leenders, H. (2020). United or divided? Antecedents of board cohesiveness in international joint ventures. Academy of Management Proceedings, 2020(1), 6 pp., Article 21123. https://doi.org/10.5465/AMBPP.2020.29

This Article is brought to you for free and open access by the Department of Management at ODU Digital Commons. It has been accepted for inclusion in Management Faculty Publications by an authorized administrator of ODU Digital Commons. For more information, please contact digitalcommons@odu.edu. 


\title{
ANTECEDENTS OF IJV BOARD COHESIVENESS: A LOOK INSIDE THE BLACK BOX
}

\author{
RENE OLIE \\ Rotterdam School of Management \\ Erasmus University \\ Burgemeester Oudlaan 50 \\ 3069 PA Rotterdam, The Netherlands \\ ELKO KLIJN \\ Old Dominion University \\ HUGO V. LEENDERS \\ Old Dominion University
}

\begin{abstract}
We investigate the antecedents of board cohesiveness in international joint ventures (IJVs). Even though corporate governance scholars have frequently emphasized the crucial role of cohesiveness for board effectiveness, cohesiveness has received limited systematic research attention. IJVs are formed by two or more independent parent organizations originating from different home countries with disparate cultural backgrounds. We argue that the inherent features related to the international and partner-specific context of these organizational forms affect board cohesiveness.
\end{abstract}

\section{INTRODUCTION}

International joint ventures are complex governance arrangements: they involve two or more independent organizations with different national and cultural backgrounds that are spanning geographic distances. The IJV board of directors plays a crucial role in managing this complexity, and needs to be a cohesive, integrated group to do this well (Barrick, Bradley, Kristof-Brown \& Colbert, 2007). Yet, we know little of what factors drive cohesiveness in boards, and in particular in those of IJVs. The prime objective of this study is to explore the international- as well as partner-specific antecedents of IJV board cohesiveness.

Board cohesiveness may affect directors' board meeting attendance and the time they spend on board activities such as collecting, exchanging, and discussing relevant information (Zhu, Wang \& Bart, 2016). It may also influence directors' commitment to their monitoring and resource provision roles (Withers, Corley \& Hillman, 2012; Zhu \& Yoshikawa, 2016). Consequently, board cohesiveness may be considered a necessary condition for board task performance (Forbes \& Milliken, 1999; Westphal \& Bednar, 2005) given that cohesive teams arguably have lower communication and coordination costs (Beal, Cohen, Burke \& McLendon, 2003; Shaw, 1981; Smith, Smith, Olian, Sims, O’Bannon, \& Scully, 1994).

Whereas cohesiveness is an important asset for all types of boards, it is particularly salient in international joint ventures because of the complex and ambiguous nature of the board's tasks. IJV boards face an inherent division of loyalties: individual board members are expected to act in the interests of the IJV, while at the same time safeguarding their respective 
parent firms' interests. This makes IJV boards almost conflict-laden by design (Hewitt, 2005; Li \& Hambrick, 2005; Singleton, 2017). The international dimension adds to this complexity. Based on prior research, cohesiveness in IJV boards can be expected to be a function of international antecedents as well as partner-specific determinants.

\section{THEORY AND HYPOTHESES}

Research shows that cohesion has an important function in work groups: it increases member satisfaction and commitment to the group and its tasks, and reduces turnover intentions (O’Reilly, Caldwell, \& Barnett, 1989). Cohesion in boards essentially reflects the "board's ability to continue working together" (Forbes \& Milliken, 1999: 492). As such, cohesion also contributes to task performance (Forbes \& Milliken, 1999; Westphal \& Bednar, 2005). More cohesive teams have lower communication and coordination costs (Beal et al., 2003; Shaw, 1981; Smith et al., 1994), and members are more willing to subjugate individual interests for team goals (Harrison, Price, Gavin \& Florey, 2002).

Despite its importance, IJV boards face several challenges in achieving high levels of cohesion. First, due to the episodic nature of their meetings, many boards can face 'process losses' (Forbes \& Milliken, 1999) which hinder smooth interactions among board members and, consequently, affect the board's cohesion and effectiveness (Boivie et al., 2016). Moreover, IJV partners and board members differ in terms of organizational affiliation, nationality, culture, ethnicity, and professional background. Research points out that greater diversity among individuals in teams can negatively affect group cohesion (Boivie et al., 2016; Harrison, Price \& Bell, 1998; Michel \& Hambrick, 1992; Milliken \& Martins, 1996; O’Reilly et al., 1989; Smith et al., 1994; Van Knippenberg \& Schippers, 2007).

IJV boards have several unique characteristics that distinguish them from conventional corporate boards. First, IJV boards and IJV directors are involved in a broader range of tasks and roles. Besides principal-agent problems (i.e., differences of interests between shareholders and management), IJV boards also face principal-principal challenges (i.e., parent firms vis-à-vis IJV management). As a result, in addition to performing the same monitoring and service roles as conventional corporate boards, they also serve as platforms for partners to align their interests and solve potential conflicts (Hewitt, 2005; Ravasi \& Zattoni, 2006). Second, IJV boards are part of de novo organizations. This means that boards are newly formed groups of directors which often do not share a history or interpersonal relationships. A final, crucial characteristic of IJV boards is their inherent factional nature. Unlike corporate boards where directors represent the same company, IJV boards are composed of groups of members that represent two or more different partner organizations. Subgroups based on company membership are likely to act as faultlines (Lau \& Murnighan, 1998), which can lead to lower team identification, conflict, and distrust among members, contributing to lower social cohesion and poorer performance (Li \& Hambrick, 2005).

\section{International antecedents of IJV board cohesiveness}

Cultural diversity. A first group of antecedents of IJV board cohesiveness is related to the international nature of these partnerships. One source is the cultural diversity among the partner firms involved in the joint venture. Greater cultural diversity among IJV partners will increase the likelihood that board members hold substantially different expectations about the 
accountability and responsibility of the board, the importance of delegation and control, as well as information sharing and decision-making practices (Bamford, 2016; Griffin, Guedhami, Kwok, Li \& Shao, 2017; Licht \& Adams, 2019). Cultural values influence perceptions and response preferences (Maznevski \& Chudoba, 2000). Moreover, cultural identity is a strong source of identification and categorization (Salk \& Brannen, 2000; Salk \& Shenkar, 2001). Social identity theory suggests that the existence of culturally identifiable groups leads to the categorization of people into insiders and outsiders. Outgroup members are seen by members of ingroups as less trustworthy, capable, and cooperative than members of the ingroup (Tajfel \& Turner, 1986). Additionally, similarity-attraction theory suggests that individuals like, trust, and interact more with persons who are like them in terms of nationality, values, beliefs, and attitudes (Byrne, 1961; Tsui \& Gutek, 1999). Because national identities of IJV directors often coincide with their organizational affiliations, organizational faultlines among directors will be further deepened by cultural faultlines.

In sum, stronger cultural diversity between IJV partners will increase cooperation challenges between partner firms (Li \& Hambrick, 2005; Salk \& Shenkar, 2001), and consequently, lower the cohesiveness among board members. Hence, we expect:

Hypothesis 1a: Ceteris paribus, there is a negative relationship between cultural diversity between the parent companies in IJVs and board cohesiveness.

Geographic distance. Another fundamental characteristic of IJVs is their geographic span. Geographic distance increases the interaction, communication, and coordination difficulties between individuals, teams, and organizations (Baaij \& Slangen, 2013). For example, Boeh and Beamish (2015) argue that the time required to travel between geographically separated locations harms performance of both wholly owned and joint venture subsidiaries, because of lower information sharing and lower trust between head office and subsidiary. Similarly, Reuer \& Lahiri (2013) argue that the likelihood of alliance formation decreases with greater geographic distance due to greater information asymmetries.

Geographic separation may also affect board cohesiveness in international joint ventures. Greater distance involves more travel time and hassles (Schotter \& Beamish, 2014; Boeh \& Beamish, 2015), which may result in fewer and shorter meetings, as well as an increased preference to replace face-to-face meetings with other means of communication such as video conferencing and phone calls. More importantly, research shows that spatial co-location is an important facilitating condition for the development of trust and knowledge flows across organizational boundaries (Bell \& Zaheer, 2007). Thus, we expect:

Hypothesis 1b: Ceteris paribus, there is a negative relationship between geographic distance between IJV partners and the joint venture and board cohesiveness.

\section{Partner-specific antecedents of board cohesiveness}

Multi-party IJVs. A second group of antecedents driving IJV board diversity and cohesion reflects the fact that joint ventures bring together two or more partners that are themselves independent organizations. A key characteristic is the number of foreign partners involved in the international joint venture. The number of IJV partners will drive the diversity in director representatives, and to some extent, also the size of the board. Multi-party IJVs are 
considered more difficult to govern because the higher number of intra- and inter-partner firm relations causes coordination and communication challenges (Garcia-Canal, Valdes-Llaneza, \& Ariño, 2003; Killing, 1983). It also increases the likelihood of strategic misalignment (Gong, Shenkar, Luo, \& Nyaw, 2007) and opportunistic behavior (Garcia-Canal et al., 2003). In line with these arguments, researchers found that IJVs with more partners are characterized by more cooperation challenges and lower short-term performance (Garcia-Canal et al., 2003; Gong et al., 2007), as well as lower survival rates (Chung \& Beamish, 2012).

As mentioned, a distinctive feature of IJV boards is their coalitional nature and the dual role of their members (Singleton, 2017). Board members can face opposing pressures regarding serving the interests of the joint venture while also acting in the best interests of the parent company that appointed them on the other hand (Bamford \& Ernst, 2005; Hewitt, 2005; Zhu \& Yoshikawa, 2016). These pressures tend to be more conflicting when multiple partners are involved given that their interests are more likely to diverge (Gong, et al., 2007) The diversity in interests represented on the board may therefore work as a divisive element. Given that the variety of parent company interests is higher in multi-party joint ventures than in dyadic joint ventures, we expect that board cohesiveness will be lower in multi-party joint ventures. Thus, we expect:

Hypothesis 2a: Ceteris paribus, there is a negative relationship between the number of IJV partners and board cohesiveness.

Business relatedness. A second partner-specific feature of international joint ventures is the similarity or dissimilarity among parent companies in terms of knowledge, resources, and capabilities which is typically a result of the reasons for their formation (Balakrishnan \& Koza, 1993; Koh \& Venkatraman, 1991; Merchant \& Schendel, 2000). Diversity of knowledge makes it attractive for a firm to team up with other international firms, but creates integration and assimilation difficulties (Phene, Fladmoe-Lindquist \& Marsh, 2006). As with national cultural diversity, greater diversity in business backgrounds among directors may also lower the odds of developing a strong, cohesive board. At the board level, having a common frame of reference, a shared language, and similar cognitive structures will enable directors to communicate and develop trusting relationships with each other (Keil, Maula, Schildt \& Zahra, 2008; Lane \& Lubatkin, 1998). Differences in human capital (e.g., education), social capital (e.g., social relations) and cognitions (e.g., beliefs and mental models) among directors will likely further reinforce social categorization processes and faultlines based on cultural diversity and geographic distance. Therefore, we expect:

Hypothesis 2b: Ceteris paribus, there is a positive relationship between business relatedness among the IJV partners and board cohesiveness.

\section{RESEARCH METHODS}

\section{Sample and data}

For the measurement of board cohesiveness, we relied on primary data which we collected through a survey in 2014. For the measurement of our international antecedents, we 
used secondary data sources. For partner-specific antecedents we used quasi-objective data obtained from the survey. Our control variables are also survey-based.

We selected an initial population of 2,222 IJVs that were formed in the 2008 - 2014 time period across 126 countries. Our sample was focused on senior executives of mostly European firms with IJV experience, either by means of establishing, managing, or overseeing them. We circulated a total of 961 questionnaires, of which 169 were returned (17.6\% response rate). Our final sample consisted of 112 IJVs located in 35 different countries.

To the extent that there are significant difficulties in identifying potential respondents in IJVs, along with the high staff turnover, the confidentiality of information, and the small size of many IJVs, we were forced to adopt a single, key informant approach. Survey research on strategic collaborations and board processes often relies on this approach given that it is usually the only way to collect information (e.g., Krishnan, Martin \& Noorderhaven, 2006; Kumar, Stern \& Anderson, 1993; Schreiner, Kale \& Corsten, 2009; Zattoni, Gnan, \& Huse 2015). We followed Campbell's (1955) suggestions to mitigate its downsides.

Based on several control mechanisms as well as post-hoc analyses, our findings appeared not to be subject to common method bias or late respondent bias (Armstrong \& Overton, 1977; Harman, 1967; Podsakoff, MacKenzie, Lee, \& Podsakoff, 2003). We also tested for independence and discriminant validity (Fornell \& Larcker, 1981).

\section{Variables and measurement}

Dependent variable. For board cohesiveness, we used a 5-item survey instrument developed in prior research (Forbes \& Milliken, 1999; O’Reilly et al., 1989; Smith et al., 1994) and adapted it to the IJV board setting $(\alpha=0.89)$.

Independent variables. Cultural diversity among IJV partners is often measured using the average cultural distance between the parent firms' home countries (e.g., Reuer et al., 2014). Because these cultural distance measures have received considerable criticism (e.g., Shenkar, 2001; Beugelsdijk, Kostova, \& Roth, 2017), we use Ronen \& Shenkar's (2013) synthesis on cultural clusters as a basis for our measure of cultural diversity (hypothesis 1a). In supplemental analysis, we explored the robustness of this measure by comparing it with more traditional distance measures.

To construct a measure for hypothesis $1 \mathrm{~b}$, we used data from the CEPII database. Geographic distance (hypothesis 1b) was calculated by using the Great Circle distance formula between the capitals of the country of origin of the partners and the IJV host country.

As for our partner-specific antecedents, we constructed a dummy variable to capture whether the IJV had more than two partners (hypothesis 2a). The variable holds a value of 0 for two party deals, and 1 if more than two partners are involved.

Finally, to test hypothesis $2 \mathrm{~b}$, we used a survey measure asking respondents to identify the industries of all joint venture partners using a pre-specified list of industries (c.f. Reuer, Klijn, \& Lioukas, 2014). We created a dummy variable, assigning a score of 1 when IJV partner firms operated in the same industry, and 0 if at least one of the partner firms did not operate in the same industry.

Control variables. We controlled for IJV size and age, the presence of IJV subcommittees, the annual number of board meetings, the proportion of insiders within the board, and the number of board members. Furthermore, we included two measures to capture alternative governance instruments that partners may implement in their IJV: prior ties and 
contractual complexity (Parkhe, 1993). We also controlled for nationality diversity (Blau, 1977) and environmental uncertainty in the host country (Reuer et al., 2014).

\section{RESULTS}

Our first set of hypotheses considers two international antecedents of IJV board cohesiveness. Consistent with hypothesis $1 \mathrm{a}$, cultural diversity between IJV partners is significantly and negatively related to IJV board cohesiveness $(\beta=-0.472, p=0.047)$. Our second hypothesis $(1 \mathrm{~b})$ is concerned with the effect of geographic distance between partners' home countries and the IJV host country on board cohesiveness. Contrary to what we hypothesized, the coefficient estimate for geographic distance is positive and strongly significant $(\beta=0.115, p=0.001)$. H1b is therefore rejected, and in the discussion section we interpret this finding and its implications.

The second set of hypotheses focuses on partnership-specific antecedents of board cohesiveness. Hypothesis $2 \mathrm{a}$, suggesting a negative relationship between the number of IJV partners and board cohesiveness, was supported $(\beta=-0.324, p=0.022)$. Consistent with our final hypothesis $(2 \mathrm{~b})$, business relatedness among the IJV partners is significantly and positively related to board cohesiveness $(\beta=0.249, \mathrm{p}=0.009)$. We conducted several supplemental analyses to ascertain the robustness of our findings.

\section{DISCUSSION}

This study makes several contributions to the alliance governance literature, and to corporate governance research on board processes more generally. First, this study addresses a central question in board research why some boards are more effective than others. Whereas there is broad consensus about the need to pay more attention to board dynamics, the research on whether and how boards work together effectively remains scant (Forbes \& Milliken, 1999; Zhu et al., 2016). Board processes are often inferred from proxies such as average team tenure and team heterogeneity (e.g., Michel \& Hambrick, 1992), but are seldomly directly investigated. The lack of cohesion in boards is seen as an important potential reason why larger boards tend to be less effective than smaller boards, or why board meeting frequency has a negative effect on firm performance (Boivie, Bednar, Aguilera, \& Andrus, 2016), but systematic evidence on board cohesion and its antecedents is lacking.

This paper also advances an emerging stream of research on IJV boards. While the importance of IJV boards for joint venture performance has long been acknowledged (Killing, 1983; Kriger, 1988; Kumar \& Seth, 1998; Leksell \& Lindgren, 1982), their role in the formal governance of IJVs has not been a topic of much theoretical development and empirical research (Reuer \& Klijn, 2018). Board processes have been "black boxed", even though the cohesiveness of IJV boards might be critical to their effectiveness (Li \& Hambrick, 2005).

\section{REFERENCES AVAILABLE FROM THE AUTHORS}

